Article

\title{
Fractionation of Lignocellulosic Residues Coupling Steam Explosion and Organosolv Treatments Using Green Solvent $\gamma$-Valerolactone
}

\author{
Mattia Gelosia *, David Ingles, Enrico Pompili, Silvia D'Antonio, Gianluca Cavalaglio (D), \\ Alessandro Petrozzi and Valentina Coccia \\ CIRIAF-Biomass Research Centre Section, University of Perugia, Via G. Duranti 67, 06125 Perugia, Italy; \\ ingles@crbnet.it (D.I.); pompili@crbnet.it (E.P.); dantonio@crbnet.it (S.D.); cavalaglio@crbnet.it (G.C.); \\ petrozzi@crbnet.it (A.P.); coccia@crbnet.it (V.C.) \\ * Correspondence: gelosia@crbnet.it; Tel.: +39-075-585-3804
}

Received: 4 July 2017; Accepted: 23 August 2017; Published: 25 August 2017

\begin{abstract}
A two-step fractionation of lignocellulosic residues of Phragmites australis in its main components (cellulose-pulp, soluble hemicellulose sugars, and lignin) is described, based on the biomass-derived solvent $\gamma$-valerolactone (GVL). The solvent used is an excellent substitute for traditional organic solvents as it is not toxic, it is renewable, and it can be recycled after the extraction process. Prior the GVL-organosolv extraction process, a steam explosion pretreatment was performed in order to break up the tight lignocellulosic structure and partially depolymerise hemicellulose into soluble sugars, making lignin easier to be solubilised. Three common extraction techniques were compared: soxhlet, closed vessel microwave-assisted, and open vessel on a hotplate stirrer. The two-step approach resulted in a cellulose-rich solid, water-soluble hemicellulose sugars and lignin-rich GVL liquor which was further purified for lignin isolation. The two best resulting pulps presented a high cellulose content $(75.47 \%$ and $78.68 \%$ ) starting from $38.13 \%$ and a content of lignin down to $11.96 \%$ and $13.09 \%$ starting from $23.02 \%$. Almost all hemicellulose was removed with a final content of $0.72 \%$ and $2.20 \%$ starting from $20.5 \%$.
\end{abstract}

Keywords: $\gamma$-valerolactone; organosolv; steam explosion; biorefineries; Phragmites australis; delignification

\section{Introduction}

The expected decrease in petroleum extraction raised interest in the development of efficient ways of using renewable carbon sources [1]. One of the most abundant biological organic materials is lignocellulose and a consistent fraction of it is to be found in the form of agricultural, forestry, municipal, and industrial waste. This residual material not only causes environmental problems, such as pollution, health issues, and safety hazards, but also represents an important renewable source [2] suitable for being used as a substrate for lignocellulosic feedstock biorefineries [3]. The feedstock used in the present work, Phragmites australis (Common reed) residues, is a good example of lignocellulosic waste from the crafting of roofs, baskets, and beach umbrellas. Phragmites australis is a perennial grass that grows in wetlands or near inland waterways. Due to its fast-growing properties, high biomass yield, and low requirement in nutrients and water, this arboreal variety is recognized as a promising feedstock [4]. Lignocellulose is a complex matrix where cellulose, hemicellulose, and lignin are closely arranged making it resistant towards both biological and chemical treatments [2]. Several pretreatment methods have been proposed in order to alter or fractionate this type of biomass and render its main components available for different conversion processes [5-10]. Although organosolv (OS) process is at present rather expensive, it can provide some valuable products [11]. Compared to other chemical 
pretreatment processes, such as dilute acid hydrolysis, where some components of the biomass are degraded, the OS process, as well as steam explosion (SE) pretreatment, fractionates the biomass so that most of its components are recoverable [12,13]. Another advantage is the possibility of recycling the solvent while in other treatments the reagents become waste with environmental issues and disposing costs. Therefore, this process suits the biorefinery concept where every fraction of the feedstock needs to be separated and valorised in order to make the whole process sustainable [14].

Recently $\gamma$-valerolactone (GVL) has been proposed as an interesting molecule because of its renewable nature, as it can be obtained from levulinic acid, which is a degradation product of structural carbohydrates present in lignocellulose $[15,16]$.

Several applications have been reported for GVL such as an additive for liquid fuels with properties similar to those showed by ethanol [16] and also as a precursor for the production of liquid alkanes [14-17]. Additionally, GVL has been described as a platform molecule for carbon-based chemicals such as 1,4 pentanediol, 2-methyltetrahydrofuran (MTHF), and methyl pentenoate, amongst others, which can be further upgraded to liquid fuels, additives, or polymers [16-21]. Moreover, GVL has been found to be a very promising solvent with a low melting point $\left(-31^{\circ} \mathrm{C}\right)$, a high boiling point $\left(207^{\circ} \mathrm{C}\right)$ and very low toxicity. It was recently employed as a solvent in catalytic conversion reactions [22-24] and also in the processing of lignocellulosic biomass [25,26].

In this article Phragmites australis residues were treated in a two-step approach, coupling SE pretreatment and the GVL-OS process, in order to obtain a cellulose-rich solid and a lignin-rich liquid phase that was further purified for lignin isolation. In this novel configuration the SE breaks down the lignocellulose structure [27] making lignin easier to be removed by the green solvent GVL. Three common extraction techniques were compared: soxhlet, closed vessel microwave-assisted, and open vessel on a hotplate stirrer.

Removing lignin from the SE pretreated solid enhances the digestibility of the substrate if it is to be used in the production of bioethanol [28,29] because of lignin's inhibitory effect due to the adsorption of enzymes. Additionally, higher ethanol yields are expected for a substrate with higher cellulose content. Another route could be the optimization of this two-step approach for pulping purposes. Furthermore, the isolated lignin and the sugars derived from hemicellulose, as well as other chemicals, like acetic acid and furfural, can be valorised through several applications listed elsewhere [28,30-32].

\section{Materials and Methods}

\subsection{Materials}

$\gamma$-valerolactone $\geq 98 \%$ and sulfuric acid solution $72 \%$ were purchased from Sigma Aldrich (St. Louis, MO, USA).

Phragmites australis processing residues were employed as a lignocellulosic substrate for the whole experimentation and they were obtained from local handicrafts in the Lake Trasimeno area (Umbria, Italy). The starting composition of the raw material was determined by National Renewable Energy Laboratory (NREL) (Golden, CO, USA) characterisation procedure [33] and the results are summarised below in Table 1.

Table 1. Phragmites australis characterisation.

\begin{tabular}{cccccccc}
\hline Hemicellulose & Cellulose & Acetyl & Lignin & Extractives & Ash & Total & Other \\
\hline $20.51 \%$ & $38.13 \%$ & $3.92 \%$ & $23.02 \%$ & $6.90 \%$ & $4.25 \%$ & $97.92 \%$ & $3.28 \%$ \\
\hline
\end{tabular}

\subsection{Methods}

Figure 1 summarises the workflow procedure followed in this experimentation. On the left of the figure are shown the main steps of the procedure i.e., SE and OS, while on the right and on the bottom are shown the secondary steps of separation, i.e., recovery, precipitation, washing, and drying. 


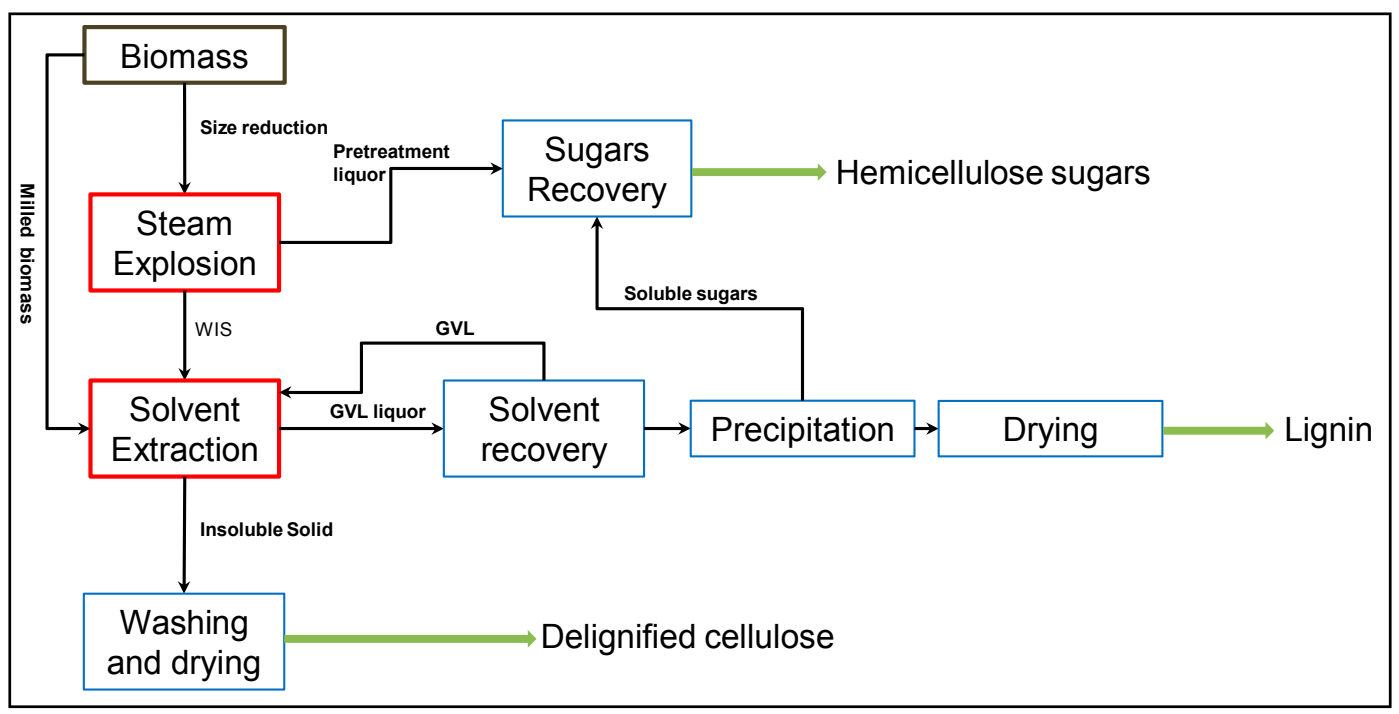

Figure 1. Flowchart of the steps followed in the experimentation.

\subsubsection{Steam Explosion}

The SE pretreatment was carried out in a pilot-scale reactor provided by Biochemtex (Tortona, Italy). The feedstock was pretreated at three different severity factors of $\log R_{0}$ 3.6, 4.0, and 4.4. The $\log \mathrm{R}_{0}$ value describes the intensity of the SE pretreatment as described by Overend et al. [34] according to Equation (1):

$$
R_{0}=t e^{\frac{T-100}{14.75}}
$$

where $t$ is the time ( $\mathrm{min})$ and $T$ is the temperature $\left({ }^{\circ} \mathrm{C}\right)$.

The output materials were divided in a water insoluble substrate (WIS), containing mainly cellulose and lignin, and a pretreatment liquor rich in hemicellulose sugars and degradation products. The WIS was washed in hot water $\left(50^{\circ} \mathrm{C}\right)$ and then treated for the GVL-OS extraction process.

\subsubsection{GVL-OS Extraction Procedures}

Different sample types were tested: (1) milled $(<0.5 \mathrm{~mm})$ and pretreated with SE at $\log \mathrm{R}_{0}$ (2) 3.6, (3) 4.0, and (4) 4.4. All samples were chipped to a size of 3-5 cm before the SE pretreatment.

Three extraction techniques were compared using GVL at a solvent/biomass ratio of 10:1. Soxhlet extraction (SOX) was performed in a traditional lab glass apparatus for six cycles and the solvent temperature measured in the top vessel was $\approx 90^{\circ} \mathrm{C}$. An open vessel extraction $(\mathrm{OV})$ was conducted on a hotplate stirrer at $150{ }^{\circ} \mathrm{C}$ for $30 \mathrm{~min}$ and $120 \mathrm{~min}$. The microwave-assisted extractions (MAE) were carried out in a Milestone ETHOS One (Sorisole, Italy) unit and the working conditions were $150{ }^{\circ} \mathrm{C}$ or $200{ }^{\circ} \mathrm{C}$ and $30 \mathrm{~min}$ or $120 \mathrm{~min}$. The OV was not tested at $200^{\circ} \mathrm{C}$ because it is close to the GVL boiling temperature. The operating conditions are summarised below in Table 2.

After the extraction procedure the insoluble solid was separated by a filtering crucible. It was then washed with clean solvent (same volume used for the extraction) in order to prevent re-precipitation of lignin [11] and then washed again with water at $50{ }^{\circ} \mathrm{C}$. Finally, the substrate was dried and weighed. Lignin-rich GVL-liquor was concentrated by means of evaporation under vacuum in order to recover GVL solvent. The lignin dissolved into the concentrated GVL-liquor was precipitated by adding water using a ratio of $1: 10(v / v)$. The precipitate was recovered by centrifugation and supernatant was analysed for the characterisation of sugars. 
Table 2. Summary of operating conditions for samples that underwent to OS treatment.

\begin{tabular}{ccccc}
\hline Sample Name & LogR $_{\mathbf{0}}$ & Extraction Technique & Time (min) & Temperature $\left({ }^{\circ} \mathbf{C}\right)$ \\
\hline Sm & 0 (milled) & SOX & 6 cycles & $\approx 90.0$ \\
S3.6 & 3.6 & SOX & 6 cycles & $\approx 90.0$ \\
S4.0 & 4 & SOX & 6 cycles & $\approx 90.0$ \\
S4.4 & 4.4 & SOX & 6 cycles & $\approx 90.0$ \\
OVAm & 0 (milled) & OV & 30.0 & 150.0 \\
OVA3.6 & 3.6 & OV & 30.0 & 150.0 \\
OVA4.0 & 4 & OV & 30.0 & 150.0 \\
OVA4.4 & 4.4 & OV & 30.0 & 150.0 \\
MAm & 0 (milled) & MAE & 30.0 & 150.0 \\
MA3.6 & 3.6 & MAE & 30.0 & 150.0 \\
MA4.0 & 4 & MAE & 30.0 & 150.0 \\
MA4.4 & 4.4 & MAE & 30.0 & 150.0 \\
MBm & $0($ milled $)$ & MAE & 30.0 & 200.0 \\
MB3.6 & 3.6 & MAE & 30.0 & 200.0 \\
MB4.0 & 4 & MAE & 30.0 & 200.0 \\
MB4.4 & 4.4 & MAE & 30.0 & 200.0 \\
OVBm & $0($ milled $)$ & OV & 120.0 & 150.0 \\
OVB3.6 & 3.6 & OV & 120.0 & 150.0 \\
OVB4.0 & 4 & OV & 120.0 & 150.0 \\
OVB4.4 & 4.4 & OV & 120.0 & 150.0 \\
MCm & $0($ milled $)$ & MAE & 120.0 & 150.0 \\
MC3.6 & 3.6 & MAE & 120.0 & 150.0 \\
MC4.0 & 4 & MAE & 120.0 & 150.0 \\
MC4.4 & 4.4 & MAE & 120.0 & 150.0 \\
MDm & $0($ milled $)$ & MAE & 120.0 & 200.0 \\
MD3.6 & 3.6 & MAE & 120.0 & 200.0 \\
MD4.0 & 4 & MAE & 120.0 & 200.0 \\
MD4.4 & 4.4 & MAE & 120.0 & 200.0 \\
\hline
\end{tabular}

\subsubsection{Characterisation of Solid and Aqueous Fractions}

All the solids obtained were characterised following the NREL analytical procedures [33]. The structural carbohydrates were quantified as their monomers, after acid hydrolysis with $\mathrm{H}_{2} \mathrm{SO}_{4}$, by Thermo Scientific Dionex Ultimate 3000 high-performance liquid chromatography (HPLC) (Thermo Fisher Scientific, Waltham, MA, USA) equipped with an Aminex Biorad HPX87H column (Bio-Rad, Hercules, CA, USA) and a refractive index detector. The acid insoluble residue (AIR) was quantified in a crucible after acid hydrolysis. Ash was quantified by burning the AIR in a muffle furnace at $575{ }^{\circ} \mathrm{C}$. Acid insoluble lignin (AIL) was determined as the difference between AIR and ash. All the aqueous fractions were characterised by HPLC following NREL analytical procedures for determination of sugars [35]. All the compounds that were not directly characterised, namely other components were quantified as the difference between the total mass of the sample and the mass of all the characterised components in the sample.

The lignin extracted $\left(L_{\text {ext }}\right)$ was quantified as the difference between AIL content in the raw material and its residual content in the sample after organosolv extraction according to Equation (2):

$$
L_{\text {ext }}=\frac{R M \times L_{R M}-I S \times L_{I S}}{R M \times L_{R M}}
$$

where $R M$ is the mass of raw material (g); $L_{R M}$ is the content of AIL (wt \%) in raw material; IS is the mass of insoluble solid after organosolv extraction (g); and $L_{I S}$ is the content of AIL (wt \%) in IS.

The cellulose enrichment $\left(C_{\text {ent }}\right)$ was determined according to Equation (3):

$$
C_{e n t}=\frac{C_{f I S}-C_{f R M}}{C_{f R M}}
$$


where $C_{f I S}$ is the percentage of cellulose in insoluble solid after organosolv extraction and $C_{f R M}$ is the percentage of cellulose in raw material.

The hemicellulose removed $H_{r e m}$ was quantified as the difference between hemicellulose content in the raw material and its residual content in the sample after organosolv extraction according to Equation (4):

$$
H_{\text {rem }}=\frac{R M \times H_{R M}-I S \times H_{I S}}{R M \times H_{R M}}
$$

where $R M$ is the mass of raw material (g); $H_{R M}$ is the content of hemicellulose (wt \%) in raw material; IS is the mass of insoluble solid after organosolv extraction $(\mathrm{g}) ; H_{I S}$ is the content of hemicellulose (wt \%) in IS.

\section{Results and Discussion}

Three extraction techniques were assessed to outline some possible routes in the scaling up of the OS process. SOX was chosen as it is a standard reference extraction technique. The OV apparatus represents a scenario of atmospheric pressure working conditions while in the MAE the closed system allows working under pressure.

Table 3 displays the characterisation of the insoluble solids obtained after the SE and GVL-OS processes where $\mathrm{C}_{\mathrm{f}}, \mathrm{H}_{\mathrm{f}}, \mathrm{L}_{\mathrm{f}}, \mathrm{A}_{\mathrm{f}}$, and $\mathrm{O}_{\mathrm{f}}$ are the percentages of cellulose, hemicellulose, lignin, ash, and other components.

Table 3. Characterisation of samples after two-step process SE and GVL-OS. $\mathrm{C}_{f}, \mathrm{E}_{\mathrm{f}}, \mathrm{L}_{\mathrm{f}}, \mathrm{A}_{\mathrm{f}}$, and $\mathrm{O}_{\mathrm{f}}$ are the content of cellulose, hemicellulose, lignin, ash, and other components into the samples.

\begin{tabular}{ccccccccc}
\hline Sample Name & $\mathbf{C}_{\mathbf{f}}$ & $\mathbf{s d}( \pm)$ & $\mathbf{H}_{\mathbf{f}}$ & $\mathbf{s d}( \pm)$ & $\mathbf{L}_{\mathbf{f}}$ & $\mathbf{s d} \mathbf{(} \pm$ & $\mathbf{A}_{\mathbf{f}}$ & $\mathbf{O}_{\mathbf{f}}$ \\
\hline Sm & $39.40 \%$ & 0.05 & $21.13 \%$ & 0.04 & $23.59 \%$ & 0.91 & $2.95 \%$ & $9.00 \%$ \\
S3.6 & $59.44 \%$ & 0.43 & $11.90 \%$ & 0.08 & $18.81 \%$ & 0.19 & $3.33 \%$ & $8.76 \%$ \\
S4.0 & $75.49 \%$ & 0.10 & $2.78 \%$ & 0.01 & $16.02 \%$ & 0.14 & $3.81 \%$ & $6.94 \%$ \\
S4.4 & $78.68 \%$ & 0.06 & $0.72 \%$ & 0.01 & $13.09 \%$ & 0.25 & $4.36 \%$ & $6.63 \%$ \\
OVAm & $38.31 \%$ & 0.22 & $21.91 \%$ & 0.15 & $23.81 \%$ & 0.07 & $3.07 \%$ & $8.98 \%$ \\
OVA3.6 & $49.75 \%$ & 0.13 & $12.84 \%$ & 0.10 & $23.24 \%$ & 1.30 & $4.35 \%$ & $7.76 \%$ \\
OVA4.0 & $70.98 \%$ & 0.27 & $3.02 \%$ & 0.07 & $15.39 \%$ & 0.16 & $4.80 \%$ & $5.10 \%$ \\
OVA4.4 & $72.41 \%$ & 0.01 & $0.51 \%$ & 0.00 & $14.13 \%$ & 0.56 & $6.48 \%$ & $6.20 \%$ \\
MAm & $40.39 \%$ & 0.16 & $21.86 \%$ & 0.04 & $22.55 \%$ & 0.11 & $2.52 \%$ & $8.51 \%$ \\
MA3.6 & $56.41 \%$ & 0.90 & $11.95 \%$ & 0.04 & $20.28 \%$ & 1.09 & $3.41 \%$ & $5.76 \%$ \\
MA4.0 & $73.50 \%$ & 0.07 & $2.65 \%$ & 0.02 & $15.68 \%$ & 0.88 & $5.47 \%$ & $2.71 \%$ \\
MA4.4 & $75.41 \%$ & 0.92 & $0.78 \%$ & 0.04 & $14.92 \%$ & 1.19 & $6.39 \%$ & $2.49 \%$ \\
MBm & $41.44 \%$ & 0.11 & $21.89 \%$ & 0.02 & $23.41 \%$ & 0.15 & $2.78 \%$ & $6.39 \%$ \\
MB3.6 & $57.69 \%$ & 0.42 & $11.62 \%$ & 0.12 & $20.12 \%$ & 0.33 & $5.25 \%$ & $3.17 \%$ \\
MB4.0 & $72.81 \%$ & 0.36 & $2.69 \%$ & 0.07 & $17.15 \%$ & 0.29 & $4.45 \%$ & $2.90 \%$ \\
MB4.4 & $75.55 \%$ & 0.99 & $0.75 \%$ & 0.04 & $13.21 \%$ & 0.41 & $6.08 \%$ & $3.45 \%$ \\
OVBm & $40.66 \%$ & 0.76 & $22.10 \%$ & 0.58 & $21.98 \%$ & 1.22 & $2.29 \%$ & $8.88 \%$ \\
OVB3.6 & $59.57 \%$ & 0.29 & $11.98 \%$ & 0.08 & $19.03 \%$ & 0.45 & $3.06 \%$ & $4.21 \%$ \\
OVB4.0 & $75.90 \%$ & 0.40 & $2.81 \%$ & 0.04 & $13.44 \%$ & 0.10 & $4.59 \%$ & $3.25 \%$ \\
OVB4.4 & $77.51 \%$ & 0.44 & $0.58 \%$ & 0.01 & $13.21 \%$ & 0.35 & $6.14 \%$ & $2.56 \%$ \\
MCm & $41.35 \%$ & 0.20 & $22.03 \%$ & 0.28 & $21.44 \%$ & 0.07 & $3.38 \%$ & $7.79 \%$ \\
MC3.6 & $56.02 \%$ & 0.33 & $12.26 \%$ & 0.03 & $19.70 \%$ & 0.26 & $4.41 \%$ & $5.63 \%$ \\
MC4.0 & $75.47 \%$ & 0.38 & $2.70 \%$ & 0 & $11.96 \%$ & 0.69 & $5.05 \%$ & $4.07 \%$ \\
MC4.4 & $74.60 \%$ & 0.36 & $0.56 \%$ & 0.01 & $12.96 \%$ & 0.68 & $6.76 \%$ & $4.78 \%$ \\
MDm & $43.15 \%$ & 0.20 & $22.59 \%$ & 0.09 & $22.24 \%$ & 0.03 & $2.16 \%$ & $5.86 \%$ \\
MD3.6 & $60.62 \%$ & 0.27 & $11.79 \%$ & 0.09 & $18.99 \%$ & 0.04 & $3.72 \%$ & $3.07 \%$ \\
MD4.0 & $76.69 \%$ & 0.03 & $2.62 \%$ & 0.01 & $12.32 \%$ & 0.30 & $4.50 \%$ & $3.20 \%$ \\
MD4.4 & $75.87 \%$ & 0.17 & $0.50 \%$ & 0 & $14.65 \%$ & 0.75 & $6.37 \%$ & $2.30 \%$ \\
\hline
\end{tabular}




\subsection{Comparison between Extraction Techniques; Effect of Time and Temperature}

As shown in Figure 2 the $L_{\text {ext }}$ did not vary significantly depending on the extraction technique. In fact, for any block at the same $\log R_{0}$ value and extraction time the results are comparable. For example, at $\log _{0} 4.0$ in the 120 min block the values are similar to each other and are all higher than those of the 30 min block suggesting that there is a small difference when using OV or MAE technique. On the other hand, at $\log _{0} 3.6$ and 4.0 the effect of the residence time in the extraction is slightly more significant than the contribution of temperature which did not present a clear relationship with the $L_{\text {ext }}$.

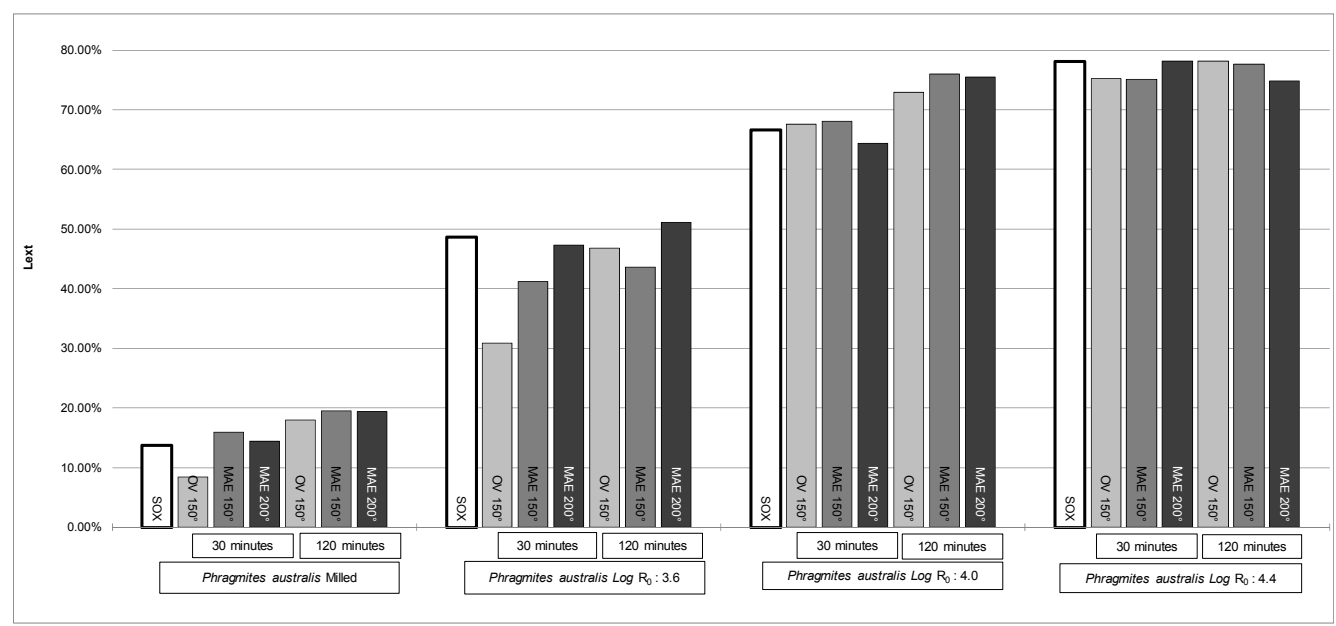

Figure 2. Overview of $L_{\text {ext }}$ comparing different extraction techniques, temperatures, and residence times.

Soxhlet extraction is not comparable in terms of temperature and time of the process because of its technical characteristics, where the temperature cannot be controlled and the extraction time depends on the number of cycles and is longer if compared to the other techniques assessed. Moreover the solvent is clean for every cycle. However, it showed good figures in terms of $L_{\text {ext }}$ and $C_{\text {ent }}$ (Figure 3).

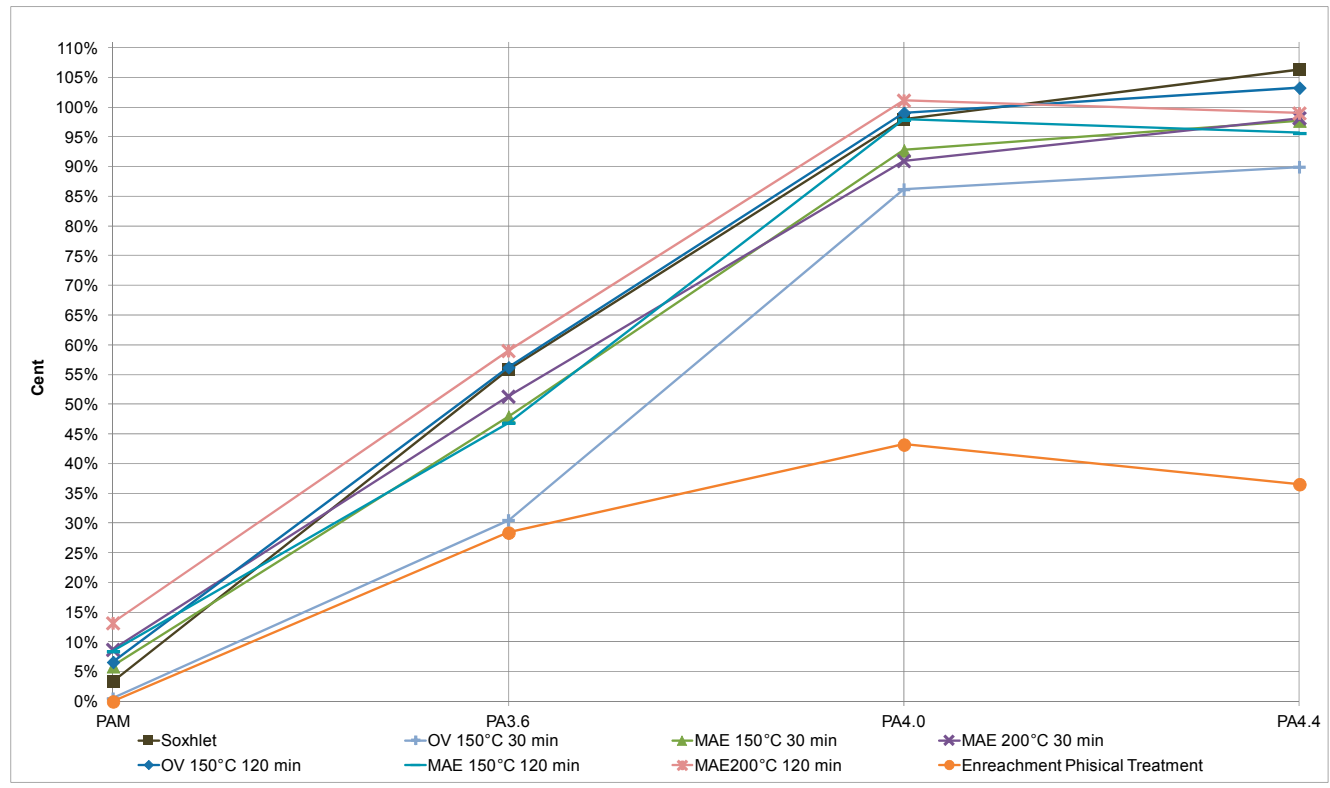

Figure 3. Cellulose enrichment after SE and two-step approach (SE and GVL-OS). PAM is milled raw Phragmites australis; PA3.6, PA4.0, and PA4.4 are WIS of Phragmites australis pretreated at increasing severity factor $\left(\log R_{0} 3.6,4.0\right.$, and 4.4$)$. 
Regarding the comparison between OV and MAE extractions, these both achieved comparable results. The advantage of working under atmospheric pressure is that there is no need to work under extremely tight conditions [11]. On the other hand microwave-assisted biorefineries according to Sobhy and Chaouky [36] are expected to lead to improved process control and higher efficiency than conventional heating systems.

These preliminary tests laid the foundations for further optimization and scaling up of the extraction method where both atmospheric pressure systems or pressurised MAE systems represent a feasible path.

\subsection{Severity Factor $\left(\log R_{0}\right)$ Effect}

According to the literature $[37,38]$ the SE pretreatment disrupts the heteropolysaccharide-lignin network and depolymerises lignin by cleaving the $\beta-O-4$ aryl ether bonds resulting in an increased solubility in alkali and organic solvents. In Figure 2 the tests are divided by $\log R_{0}$ and confirmed that delignification increased by increasing the SE pretreatment severity. In fact, in the results for the milled sample, which did not undergo SE, the $L_{\text {ext }}$ values were the lowest. However, it can also be seen that the delignification rate reached a plateau between $\log R_{0} 4.0$ and $\log R_{0} 4.4$. In fact, as shown in Table 3 for some trials e.g., OVB4.0 and OVB4.4 the $L_{\text {ext }}$ values are similar, respectively, $75.98 \%$ and $77.61 \%$, and in some cases, such as MD4.0 and MD4.4, the value is higher for the former, $75.52 \%$ and $74.89 \%$, respectively. This is probably due to reduction of lignin solubility in harsh conditions and condensation of a glycosidic material, described as pseudo-lignin [39], which increases the mass of residual lignin into the insoluble solid after the GVL extraction. It is also likely that at a severity factor of 4.0 the total extractable lignin is already easy to solubilise meaning that it is not worthwhile to push the SE pretreatment to high conditions. Another interesting trend is the one showed by all the tests at $\log R_{0} 4.4$ which all showed similar $L_{\text {ext }}$. This suggests that at $\log R_{0} 4.4$, the harsh steam explosion conditions altered the biomass structure greatly, so that lignin was easily extracted regardless of the experimental conditions used (time, temperature, and extraction technique) in the extraction step.

In order to evaluate the effect of coupling SE and GVL-OS processes, the cellulose enrichment into insoluble solid was plotted against the $\operatorname{LogR}_{0}$ value together with the cellulose enrichment into WIS obtained by the sole SE (Figure 3).

It can be seen that the SE pretreatment not only makes lignin easier to solubilise but also enriches the substrate in cellulose. This effect increases with the $\log R_{0}$ because of the hydrolysis of the glycosidic bonds in hemicelluloses and, to a lesser extent, in the cellulose [38]. In fact the samples showed an enrichment in cellulose due to the loss of hemicelluloses until $\log _{0} 4.0$ and then a decrease in cellulose at $\log \mathrm{R}_{0} 4.4$ because of the harsher conditions. This confirms that it might be counter-productive to work at high severity factors. The other curves in the graph showed a small increase in cellulose fraction for the milled sample. On the other hand, good enrichments were achieved for the SE pretreated samples, especially at $\log R_{0} 4.0$, where some tests reached cellulose overall enrichments above $100 \%$ (see Table 3 ) meaning that the cellulose fraction was doubled in the recovered solid. In this graph it is also confirmed that the effect of the severity factor (before reaching the plateau at 4.0) is the main contribution to the substrate fractionation. In fact all the curves representing the different extraction techniques and process variables showed the same trend and rather similar results. The $C_{\text {ent }}$ rose until $\log R_{0} 4.0$ whereas between this value and $\log R_{0} 4.4$ the gain was negligible.

It is also important to consider the effect of this process on hemicellulose. This structural polymer is more susceptible to hydrolysis compared to cellulose and lignin. Hence, the majority of hemicellulose is hydrolysed and solubilised in the form of monomeric and oligomeric sugars by the first SE step, whilst the second step is less aggressive towards the degradation of hemicellulose. These considerations are confirmed by the results displayed in Figure 4, which shows the removal of hemicellulose from the substrate in the worst and best case (OV $150{ }^{\circ} \mathrm{C} 30 \mathrm{~min}$ on the left and MAE $200{ }^{\circ} \mathrm{C} 120 \mathrm{~min}$ on the right). All the other results lie between these two. The majority of hemicellulose was removed in the SE step. Part of it was recovered in the pretreatment liquor (grey segment) while the rest was degraded into 
other substances (dark grey segment). The light grey segment represents the hemicellulose removed by the solvent extraction and it can be further recovered. For the samples which did not undergo SE (OVAm and $\mathrm{MDm}$ ) the solvent extraction showed very poor removal of hemicellulose. The double treated samples showed increasing removals of hemicellulose with increasing $\log \mathrm{R}_{0}$ reaching $98 \%$ at 4.4. However, at this $\log R_{0}$ most of the hemicellulose was degraded $(92 \%)$. On the contrary, at $\log R_{0}$ $3.6,37 \%$ of hemicellulose was recovered in the pretreatment liquor, whilst only $13 \%$ of it was degraded.

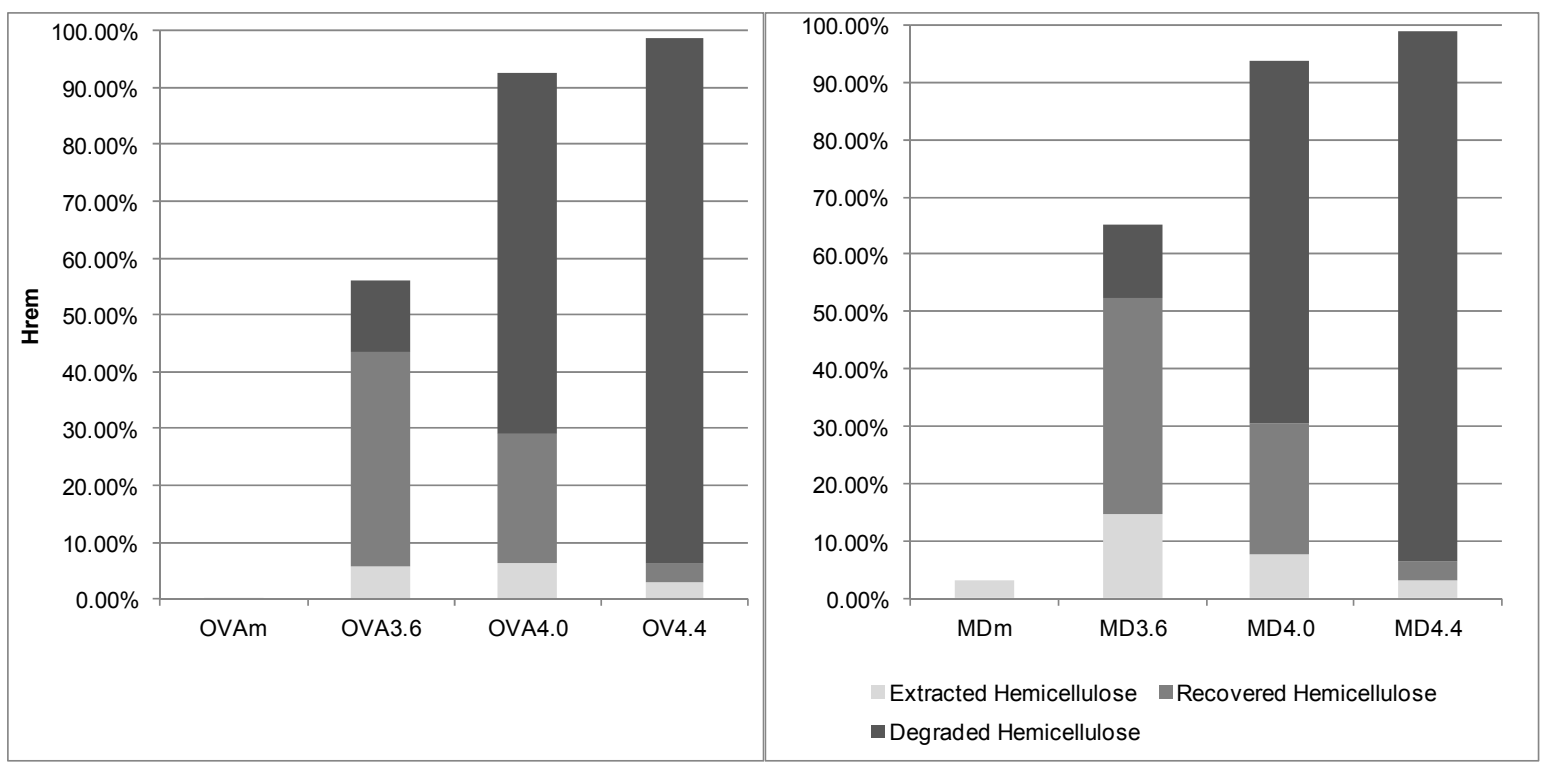

(a)

(b)

Figure 4. Comparison of $H_{\text {rem }}$ between OV (a) and MAE (b) methods. The $H_{\text {rem }}$ plot (a and b) is divided into three parts: the fraction recovered into the pretreatment liquor (recovered hemicellulose), the fraction extracted by OS treatment (extracted hemicellulose), and the fraction degraded by SE pretreatment.

\section{Conclusions}

The coupling of steam explosion and organic solvent extraction with GVL showed good results in terms of delignification $(75-78 \%)$ and cellulose enrichment $(\approx 100 \%)$ of Phragmites australis. Pulps obtained presented a high cellulose content of up to $78.68 \%$ and a content of lignin and hemicellulose down to $11.96 \%$ and $0.50 \%$, respectively. These results represent a promising starting point for a further optimisation of the process.

A steam explosion pretreatment of $\log R_{0} 4.0$ was sufficient to maximise the delignification by GVL-OS process, while no significant effects were observed in the milled feedstock. Anyway the SE conditions need to be further optimised, between $\log R_{0} 3.6$ and 4.0, to reduce the degradation of hemicellulose sugars. The GVL-OS process showed similar figures both at high temperature with short time $\left(200^{\circ} \mathrm{C}-30 \mathrm{~min}\right)$ and low temperature with long time $\left(150{ }^{\circ} \mathrm{C}-120 \mathrm{~min}\right)$, meaning that SE pretreatment played a critical role in Phragmites australis fractionation. Regarding the extraction techniques assessed, all showed good figures of the variables investigated but the MAE seemed the less time consuming and the best in terms of conditions control.

The two-step process proposed suits the biorefinery concept where all the components of biomass are recovered and can be valorised and it can be applied for those applications where high cellulose content materials are needed, e.g., in the production of cellulosic ethanol or paper production. In fact the materials obtained can be suitable to be hydrolysed to obtain monomers with enzymatic cocktails, removing the inhibitory effect of both hemicellulose and lignin or, after further optimisation, used in the paper industry. 
Author Contributions: David Ingles and Silvia D'Antonio coordinated the design of the experiments, supervised the laboratory experimentation and wrote the article. Mattia Gelosia supervised the laboratory experimentation and analyzed the data. Enrico Pompili performed the laboratory experimentations. Alessandro Petrozzi, Valentina Coccia and Gianluca Cavalaglio supervised the research activities and the article preparation.

Conflicts of Interest: The authors declare no conflict of interest.

\section{Abbreviations}

GVL $\quad \gamma$-Valerolactone;

OS Organosolv;

SE Steam explosion;

WIS Water insoluble substrate;

SOX Soxhlet extraction;

OV Open vessel extraction;

MAE Microwave assisted extraction;

$\mathrm{C}_{\mathrm{f}} \quad$ Final percentage of cellulose in two-step treated sample;

$\mathrm{H}_{\mathrm{f}} \quad$ Final percentage of hemicellulose in two-step treated sample;

$\mathrm{L}_{\mathrm{f}} \quad$ Final percentage of lignin in two-step treated sample;

$\mathrm{A}_{\mathrm{f}} \quad$ Final percentage of ash in two-step treated sample;

$\mathrm{O}_{\mathrm{f}} \quad$ Final percentage of other components in two-step treated sample;

$H_{\text {rem }} \quad$ Removed hemicellulose in respect of initial hemicellulose content;

$L_{\text {ext }} \quad$ Extracted lignin in respect of initial lignin content;

$C_{\text {ent }} \quad$ Enrichment of cellulose in respect of initial cellulose content.

\section{References}

1. Gallezot, P. Conversion of biomass to selected chemical products. Chem. Soc. Rev. 2012, 41, 1538-1558. [CrossRef] [PubMed]

2. Taherzadeh, M.J.; Karimi, K. Pretreatment of lignocellulosic wastes to improve ethanol and biogas production: A review. Int. J. Mol. Sci. 2008, 9, 1621-1651. [CrossRef] [PubMed]

3. Luo, L.; van der Voet, E.; Huppes, G. Biorefining of lignocellulosic feedstock-Technical, economic and environmental considerations. Bioresour. Technol. 2010, 101, 5023-5032. [CrossRef] [PubMed]

4. Sathitsuksanoh, N.; Zhu, Z.; Templeton, N.; Rollin, J.A.; Harvey, S.P.; Zhang, Y.H.P. Saccharification of a Potential Bioenergy Crop, Phragmites australis (Common Reed), by Lignocellulose Fractionation Followed by Enzymatic Hydrolysis at Decreased Cellulase Loadings. Ind. Eng. Chem. Res. 2009, 48, 6441-6447. [CrossRef]

5. Mosier, N.; Wyman, C.; Dale, B.; Elander, R.; Lee, Y.Y.; Holtzapple, M.; Ladisch, M. Features of promising technologies for pretreatment of lignocellulosic biomass. Bioresour. Technol. 2005, 96, 673-686. [CrossRef] [PubMed]

6. Alvira, P.; Tomás-Pejó, E.; Ballesteros, M.; Negro, M.J. Pretreatment technologies for an efficient bioethanol production process based on enzymatic hydrolysis: A review. Bioresour. Technol. 2010, 101, 4851-4861. [CrossRef] [PubMed]

7. Mood, S.H.; Golfeshan, A.H.; Tabatabaei, M.; Jouzani, G.S.; Najafi, G.H.; Gholami, M.; Ardjmand, M. Lignocellulosic biomass to bioethanol, a comprehensive review with a focus on pretreatment. Renew. Sustain. Energy Rev. 2013, 27, 77-93. [CrossRef]

8. Rossi, F.; Nicolini, A. A cylindrical small size molten carbonate fuel cell: Experimental investigation on materials and improving performance solutions. Fuel Cells 2009, 9, 170-177. [CrossRef]

9. Cotana, F.; Rossi, F.; Nicolini, A. A new geometry high performance small power MCFC. J. Fuel Cell Sci. Technol. 2004, 1, 25-29. [CrossRef]

10. Rossi, F.; Nicolini, A. Experimental investigation on a novel electrolyte configuration for cylindrical molten carbonate fuel cells. J. Fuel Cell Sci. Technol. 2011, 8, 051012. [CrossRef]

11. Zhao, X.; Cheng, K.; Liu, D. Organosolv pretreatment of lignocellulosic biomass for enzymatic hydrolysis. Appl. Microb. Biotechnol. 2009, 82, 815-827. [CrossRef] [PubMed] 
12. Avellar, B.K.; Glasser, W.G. Steam-assisted biomass fractionation. I. Process considerations and economic evaluation. Biomass Bioenergy 1998, 14, 205-218. [CrossRef]

13. García, A.; Alriols, M.G.; Llano-Ponte, R.; Labidi, J. Energy and economic assessment of soda and organosolv biorefinery processes. Biomass Bioenergy 2011, 35, 516-525. [CrossRef]

14. Huang, H.J.; Ramaswamy, S.; Tschirner, U.W.; Ramarao, B.V. A review of separation technologies in current and future biorefineries. Sep. Purif. Technol. 2008, 62, 1-21. [CrossRef]

15. Wettstein, S.G.; Alonso, D.M.; Chong, Y.; Dumesic, J.A. Production of levulinic acid and gamma-valerolactone (GVL) from cellulose using GVL as a solvent in biphasic systems. Energy Environ. Sci. 2012, 5, 8199-8203. [CrossRef]

16. Alonso, D.M.; Wettstein, S.G.; Dumesic, J.A. Gamma-valerolactone, a sustainable platform molecule derived from lignocellulosic biomass. Green Chem. 2013, 15, 584-595. [CrossRef]

17. Wettstein, S.G.; Alonso, D.M.; Gürbüz, E.I.; Dumesic, J.A. A roadmap for conversion of lignocellulosic biomass to chemicals and fuels. Curr. Opin. Chem. Eng. 2012, 1, 218-224. [CrossRef]

18. Bond, J.Q.; Alonso, D.M.; Wang, D.; West, R.M.; Dumesic, J.A. Integrated Catalytic Conversion of $\gamma$-Valerolactone to Liquid Alkenes for Transportation Fuels. Science 2010, 327, 1110-1114. [CrossRef] [PubMed]

19. Hasan, M.; Viktória, F.; Róbert, T.; Andrea, B.; László, T.M.; István, T.H. Integration of Homogeneous and Heterogeneous Catalytic Processes for a Multi-step Conversion of Biomass: From Sucrose to Levulinic Acid, $\gamma$-Valerolactone, 1,4-Pentanediol, 2-Methyl-tetrahydrofuran, and Alkanes. Top. Catal. 2008, 48, 49-54.

20. Dutta, S.; Pal, S. Promises in direct conversion of cellulose and lignocellulosic biomass to chemicals and fuels: Combined solvent-nanocatalysis approach for biorefinary. Biomass Bioenergy 2014, 62, 182-197. [CrossRef]

21. Horvath, I.T.; Mehdi, H.; Fabos, V.; Boda, L.; Mika, L.T. [gamma]-Valerolactone-a sustainable liquid for energy and carbon-based chemicals. Green Chem. 2008, 10, 238-242. [CrossRef]

22. Horvath, I.T. Solvents from nature. Green Chem. 2008, 10, 1024-1028. [CrossRef]

23. Alonso, D.M.; Wettstein, S.G.; Mellmer, M.A.; Gurbuz, E.I.; Dumesic, J.A. Integrated conversion of hemicellulose and cellulose from lignocellulosic biomass. Energy Environ. Sci. 2013, 6, 76-80. [CrossRef]

24. Zhang, L.; Yu, H.; Wang, P.; Li, Y. Production of furfural from xylose, xylan and corncob in gamma-valerolactone using $\mathrm{FeCl} 3 \cdot 6 \mathrm{H} 2 \mathrm{O}$ as catalyst. Bioresour. Technol. 2014, 151, 355-360. [CrossRef] [PubMed]

25. Luterbacher, J.S.; Rand, J.M.; Alonso, D.M.; Han, J.; Youngquist, J.T.; Maravelias, C.T.; Pfleger, B.F.; Dumesic, J.A. Nonenzymatic Sugar Production from Biomass Using Biomass-Derived $\gamma$-Valerolactone. Science 2014, 343, 277-280. [CrossRef] [PubMed]

26. Lê, H.Q.; Ma, Y.; Borrega, M.; Sixta, H. Wood biorefinery based on $\gamma$-valerolactone/water fractionation. Green Chem. 2016, 18, 5466-5476. [CrossRef]

27. Cotana, F.; Cavalaglio, G.; Gelosia, M.; Coccia, V.; Petrozzi, A.; Nicolini, A. Effect of Double-Step Steam Explosion Pretreatment in Bioethanol Production from Softwood. Appl. Biochem. Biotechnol. 2014, 174, 156-167. [CrossRef] [PubMed]

28. Pan, X.; Arato, C.; Gilkes, N.; Gregg, D.; Mabee, W.; Pye, K.; Xiao, Z.; Zhang, X.; Saddler, J. Biorefining of softwoods using ethanol organosolv pulping: Preliminary evaluation of process streams for manufacture of fuel-grade ethanol and co-products. Biotechnol. Bioeng. 2005, 90, 473-481. [CrossRef] [PubMed]

29. Koo, B.W.; Min, B.C.; Gwak, K.S.; Lee, S.M.; Choi, J.W.; Yeo, H.; Choi, I.G. Structural changes in lignin during organosolv pretreatment of Liriodendron tulipifera and the effect on enzymatic hydrolysis. Biomass Bioenergy 2012, 42, 24-32. [CrossRef]

30. Zhang, Y.H.P.; Ding, S.Y.; Mielenz, J.R.; Cui, J.B.; Elander, R.T.; Laser, M.; Himmel, M.E.; McMillan, J.R.; Lynd, L.R. Fractionating recalcitrant lignocellulose at modest reaction conditions. Biotechnol. Bioeng. 2007, 97, 214-223. [CrossRef] [PubMed]

31. Wang, G.; Chen, H. Fractionation and characterization of lignin from steam-exploded corn stalk by sequential dissolution in ethanol-water solvent. Sep. Purif. Technol. 2013, 120, 402-409. [CrossRef]

32. Lora, J.; Glasser, W. Recent Industrial Applications of Lignin: A Sustainable Alternative to Nonrenewable Materials. J. Polym. Environ. 2002, 10, 39-48. [CrossRef]

33. Sluiter, J.; Sluiter, A. Summative Mass Closure; NREL, NREL/TP-510-48087; National Renewable Energy Laboratory: Golden, CO, USA, 2010; pp. 1-10. 
34. Overend, R.; Chornet, E.; Gascoigne, J. Fractionation of lignocellulosics by steam-aqueous pretreatments. Philos. Trans. R. Soc. Lond. Ser. A Math. Phys. Sci. 1987, 321, 523-536. [CrossRef]

35. Sluiter, A.; Hames, B.; Ruiz, R.; Scarlata, C.; Sluiter, J.; Templeton, D. Determination of Sugars, Byproducts, and Degradation Products in Liquid Fraction Process Samples; National Renewable Energy Laboratory: Golden, CO, USA, 2006.

36. Sobhy, A.; Chaouki, J. Microwave-assisted biorefinery. In Proceedings of the 4th International Conference on Safety \& Environment in Process Industry, Florence, Italy, 14-17 March 2010; Volume 19.

37. Donaldson, L.A.; Wong, K.K.Y.; Mackie, K.L. Ultrastructure of steam-exploded wood. Wood Sci. Technol. 1988, 22, 103-114. [CrossRef]

38. Li, J.; Henriksson, G.; Gellerstedt, G. Lignin depolymerization/repolymerization and its critical role for delignification of aspen wood by steam explosion. Bioresour. Technol. 2007, 98, 3061-3068. [CrossRef] [PubMed]

39. Sannigrahi, P.; Kim, D.H.; Jung, S.; Ragauskas, A. Pseudo-lignin and pretreatment chemistry. Energy Environ. Sci. 2011, 4, 1306-1310. [CrossRef]

(C) 2017 by the authors. Licensee MDPI, Basel, Switzerland. This article is an open access article distributed under the terms and conditions of the Creative Commons Attribution (CC BY) license (http://creativecommons.org/licenses/by/4.0/). 